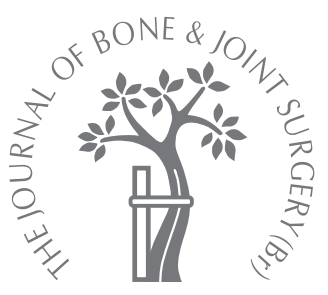

R. Hayashi,

E. Kondo,

H. Tohyama,

T. Saito,

K. Yasuda

From Hokkaido

University School of

Medicine, Sapporo,

Japan

\title{
In vivo local administration of osteogenic protein-1 increases structural properties of the overstretched anterior cruciate ligament with partial midsubstance laceration
}

\author{
A BIOMECHANICAL STUDY IN RABBITS
}

\begin{abstract}
We report the effects of local administration of osteogenic protein-1 on the biomechanical properties of the overstretched anterior cruciate ligament in an animal model. An injury in the anterior cruciate ligament was created in $\mathbf{4 5}$ rabbits. They were divided into three equal groups. In group 1, no treatment was applied, in group II, phosphate-buffered saline was applied around the injured ligament, and in group III, $12.5 \mu \mathrm{g}$ of osteogenic protein-1 mixed with phosphate-buffered saline was applied around the injured ligament. A control group of 15 rabbits was assembled from randomly-selected injured knees from among the first three groups. Each rabbit was killed at 12 weeks.
\end{abstract}

The maximum load and stiffness of the anterior cruciate ligament was found to be significantly greater in group III than either group 1 ( $p=0.002, p=0.014)$ or group II ( $p=0.032, p=0.025)$. The tensile strength and the tangent modulus of fascicles from the ligament were also significantly greater in group III than either group I $(p=0.002, p=0.0174)$ or II ( $p=0.005, p=0.022)$.

The application of osteogenic protein-1 enhanced the healing in the injured anterior cruciate ligament, but compared with the control group the treated ligament remained lengthened. The administration of osteogenic protein-1 may have a therapeutic role in treating the overstretched anterior cruciate ligament.

R. Hayashi, MD, Orthopaedic Surgeon

= T. Saito, MD, PhD, Professor and Chairman

Department of Orthopaedic Surgery

Yokohama City University School of Medicine, Fukuura 3-9, Kanazawa-ku, Yokohama City, Kanagawa Prefecture, 236-0004, Japan.

E. Kondo, MD, PhD, Orthopaedic Surgeon - $\mathrm{H}$. Tohyama, $\mathrm{MD}, \mathrm{PhD}$, Associate Professo

= K. Yasuda, MD, PhD, Professor and Chairman Department of Sports Medicine and Joint Reconstruction Surgery

Hokkaido University School of Medicine, Kita-15 Nishi-7, Kita-ku, Sapporo, 060-8638, Japan.

Correspondence should be sent to Professor K. Yasuda; e-mail: yasukaz@med.hokudai.ac.jp

(C)2008 British Editorial Society of Bone and Joint Surgery doi:10.1302/0301-620X.90B10. $20924 \$ 2.00$

$J$ Bone Joint Surg [Br]

2008;90-B:1392-400.

Received 15 February 2008;

Accepted 30 April 2008
Stretching of the anterior cruciate ligament (ACL) with partial midsubstance laceration and permanent elongation frequently occurs in various types of athletic accidents. ${ }^{1}$ The healing potential of the ACL is poor, and there are no therapeutic options for repairing the partially-injured portion immediately after this type of injury. The only current treatment option is transplantation of tendon tissue after resection of the injured ligament. However, this may not be appropriate as ACL reconstruction is an invasive procedure. ${ }^{2,3}$ Little has been done to develop an alternative, less invasive treatment that can repair the injured portion and preserve the uninjured ligamentous tissue. One reason is that there are no appropriate models for this type of ACL injury. Recently, we have established such a model which can be created with a quantitative technique. ${ }^{4}$ Using this model, we reported that the local application of transforming growth factor (TGF)- $\beta 1$ significantly inhibits the reduction of biomechanical properties in the partially-injured ACL. ${ }^{5}$ However, the intra-articular application of TGF- $\beta 1$ induces osteoarthritic changes in the knee joint. ${ }^{6-8}$ Therefore, we must seek an alternative growth factor that can enhance the healing process of the injured ACL with no detrimental effect to the knee joint.

We have investigated osteogenic protein-1 (OP-1) as an alternative factor. This has been safely applied clinically for the treatment of nonunion of bone, to provide spinal fusion, and in cartilage regeneration. ${ }^{9-11}$ Recently it has been reported that the local application of OP-1 significantly enhances cell proliferation and mRNA expression of several biochemical markers in a ligament cell culture model, ${ }^{12}$ and it is well known that OP-1 induces new bone and cartilage formation in vivo. ${ }^{11,13-15}$

We hypothesised that the local administration of OP-1 would significantly increase the mechanical properties of fascicles in the overstretched ACL with partial midsubstance laceration and permanent elongation in vivo, leading to an increased strength of the whole overstretched ACL. The purpose of this biomechanical study was to test this hypothesis. 


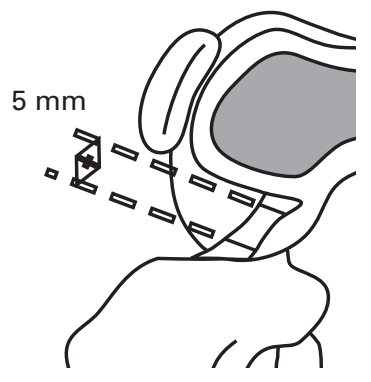

Fig. 1a

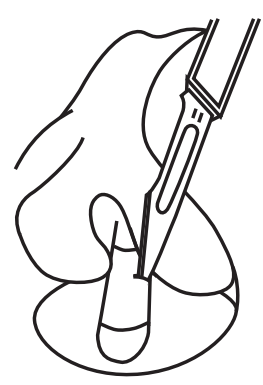

Fig. 1b

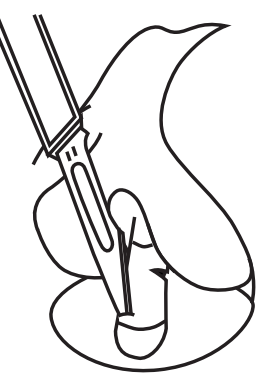

Fig. 1c

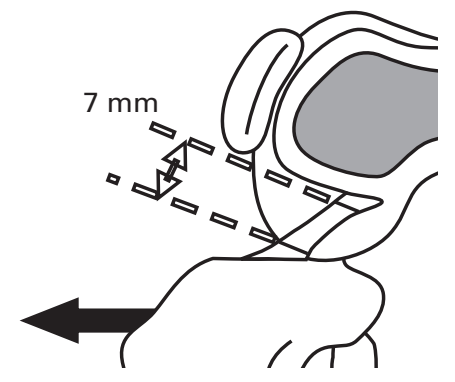

Fig. 1d

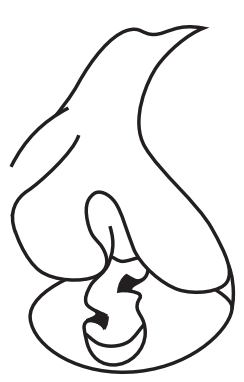

Fig. 1e

Diagrams showing a) operative treatment to create the elongation-type anterior cruciate ligament injury with laceration, the distance between the two lines (approximately $5 \mathrm{~mm}$ ) was measured at $90^{\circ}$ of knee flexion under an anterior drawer force of $10 \mathrm{~N}$. b) and c) the anteromedial and posterolateral halves of the right anterior cruciate ligament were transected with a scalpel at the proximal and distal one-third levels, respectively. d) a surgeon manually applied an anterior drawer force, monitoring the length between the two marker lines, so that the anterior cruciate ligament was elongated by $2 \mathrm{~mm}$ for five minutes. e) The anterior cruciate ligament became slack after the anterior drawer force was removed.

\section{Materials and Methods}

A total of 45 skeletally-mature female Japanese White rabbits (Kitayama Labes Co., Ltd, Ina City, Japan) with a mean weight of $3.7 \mathrm{~kg}$ (SD 0.3) were used in this study, which was carried out at the Institute of Animal Experimentation, Hokkaido University School of Medicine, under the Rules and Regulations of the Animal Care and Use Committee. ${ }^{16}$ In each animal, the right ACL was injured using the quantitative technique described ${ }^{4}$ under general anaesthesia and aseptic conditions. The 45 rabbits were then randomly divided into three groups of 15 animals each. In addition, a fourth group of controls using contralateral knees was created. In group I, no treatment was performed for the injured ACL in order to obtain the control data on the natural course of the injury. In group II, $0.2 \mathrm{ml}$ phosphate-buffered saline (PBS) was applied as the sham treatment around the injured ACL. In group III, $12.5 \mu \mathrm{g}$ OP-1 (R\&D Systems, Minneapolis, Minnesota) were applied with $0.2 \mathrm{ml} \mathrm{PBS}$ around the injured ACL. This dose of OP-1 was chosen based on an in vivo study which showed that $25 \mu \mathrm{g}$ exogenous OP-1 improved tendon integration in sheep models. ${ }^{17}$ In group IV, 15 left knees were randomly harvested from all the rabbits to obtain normal control data. All the animals were killed with an overdose of intravenous barbiturate at 12 weeks after surgery. In each group, 12 of the 15 rabbits were used for biomechanical evaluation, and the remaining three were used for histological observation. In the biomechanical evaluation, seven knees were used for mechanical evaluation of the femoral ACL-tibial complex, and the other five were used for mechanical evaluation of fascicles harvested from the ACL. The latter evaluation was conducted to discover whether the OP-1 mainly affected collagen fibrils themselves or the minor collagens and proteoglycans that were present between fibrils, based on previous biomechanical studies on structural properties of the tendon/ ligament tissue. ${ }^{18-22}$
Surgical procedure and intra-operative and post-operative treatments. Surgery was performed under anaesthesia induced by an intravenous injection of pentobarbital $(25 \mathrm{mg} / \mathrm{kg})$. In each animal, the right knee was positioned in $90^{\circ}$ of flexion by stabilising the lower leg attached to an operating table. In a sterile fashion, the ACL was exposed through a medial parapatellar approach. Two marker lines were drawn on the surface of the ACL using a black stain (nigrosine). One of the two lines was $2 \mathrm{~mm}$ distal to the femoral attachment of the ACL, and the other was $2 \mathrm{~mm}$ proximal to the tibial attachment. The normal length of the ligament was approximately $10 \mathrm{~mm}$. An injury was then created on the right ACL using the following quantitative technique. ${ }^{4}$ An anterior drawer force of $10 \mathrm{~N}$ was applied to the tibia at $90^{\circ}$ of knee flexion (Fig. 1a), and the distance between the two lines (generally approximately $5 \mathrm{~mm}$ ) was measured with a vernier caliper (Mitutoyo, Kanagawa, Japan). The anteromedial and posterolateral halves of the ACL were transected with a scalpel at the proximal and the distal one-third levels, respectively, between the two marker lines (Figs $1 \mathrm{~b}$ and 1c). The surgeon then manually increased the anterior drawer force, monitoring the intermarker length, which was continuously measured by an assistant. When the length was elongated by $2 \mathrm{~mm}$ from the initial length, the surgeon maintained this elongation for five minutes (Fig. 1d). The ACL became slack after the anterior drawer force was removed (Fig. 1e). Finally, the length between the two marker lines was measured again under the $10 \mathrm{~N}$ anterior drawer force. The length had been increased by a mean of $1.0 \mathrm{~mm}$ (SD 0.1), representing a mean lengthening of $19.8 \%$ (SD 2.0) over the initial length. The joint capsule and the skin were closed in layers with 3-0 nylon and an antiseptic spray dressing was applied. No immobilisation was applied after surgery, and the animals were allowed unrestricted daily activities in their cages, which measured $52 \mathrm{~cm}$ in width, $35 \mathrm{~cm}$ in height, and $33 \mathrm{~cm}$ in depth. 
Mechanical testing of the femoral ACL-tibial complex. At the time of death, the hind limbs of each animal were disarticulated at the hip joint. Each specimen was stored at $-80^{\circ} \mathrm{C}$. Before mechanical testing, each knee was thawed overnight at $4^{\circ} \mathrm{C}$. In order to determine the anteroposterior translation of the knee, the femoral-ACL-tibial complex, comprising a $45 \mathrm{~mm}$ long femur and a $60 \mathrm{~mm}$ long tibia, was removed from the hind limb. All the surrounding muscles were carefully removed, avoiding injury to the joint capsule and ligaments. The femur and the tibia were separately mounted in cylindrical aluminium tubes $25 \mathrm{~mm}$ in diameter and $30 \mathrm{~mm}$ in length, using polymethylmethacrylate resin. The specimen was mounted on a speciallydesigned testing device having three degrees of freedom (anteroposterior, mediolateral, and proximal-distal translations), which was attached to a tensile tester (RTC-1210, Orientec, Oakabe, Japan). ${ }^{4}$ This device allowed unrestricted movement of the tibia relative to the femur in the proximal-distal direction using a frictionless $\mathrm{X}-\mathrm{Y}$ table, so that no compressive load was generated during the displacement measurements. A total of four cycles of anteroposterior shear loads of $15 \mathrm{~N}$ were applied to the knee specimens at $30^{\circ}, 60^{\circ}$ and $90^{\circ}$ of flexion, respectively with a crosshead speed set at $5 \mathrm{~mm} / \mathrm{min}$. The specimen was kept moistened throughout the test period with a physiological saline solution spray. Load-elongation curves were drawn with an X-Y recorder (Model 3023, Yokogawa, Tokyo, Japan). The displacement of the femur relative to the tibia with $10 \mathrm{~N}$ anteroposterior loads was defined as the anteroposterior translation of the knee at each angle of flexion. We performed a reproducibility analysis of the anteroposterior displacement measurement of five normal rabbit knees. In this analysis, we measured the displacement in a sequential order, at $30^{\circ}, 60^{\circ}, 90^{\circ}$ and $30^{\circ}$ (as a repeated measure), respectively. The mean difference in displacement between the first $30^{\circ}$ and the repeated $30^{\circ}$ measurements was $0.1 \mathrm{~mm}$ (SD 0.3).

Next, the joint capsule and all ligaments except for the ACL were carefully dissected in each specimen. The femur was clamped with an alligator jaw attached to a steel stand, and the tibia was suspended from the femur by the ACL. A weight was attached to the distal end of the tibia so that a $0.5 \mathrm{~N}$ load was applied to the ACL. The femur was included so that the knee was flexed at $45^{\circ}$. The length of the ACL was measured with a vernier caliper at the anterior, posterior, medial and lateral aspects, respectively. The mean of the four values was defined as the length of the ACL. ${ }^{23}$ The cross-sectional area of the ACL was measured under the same condition as the optical non-contact method using a change-coupled device camera (WV-BD400, Panasonic, Osaka, Japan) and a video dimension analyser (HTVC1170, Hamamatsu Photonics, Tokyo, Japan), as reported by Yamamoto et al. ${ }^{19}$ Briefly, the medial femoral condyle and a portion of the lateral femoral condyle distal to the ACL insertion were resected for visualisation with the video dimension analyser. The femur was attached to the stepping motor, and a constant tensile load of $0.5 \mathrm{~N}$ was applied to the ACL by suspending a weight to the tibia. The femur was rotated with the stepping motor set at $5^{\circ}$ angular increments through $360^{\circ}$, and the corresponding profile width of the ACL was recorded with the video dimension analyser. The cross-sectional shape of the ACL was reconstructed using a computer algorithm. The measurement was made at the middle of the ACL to quantify a part of the gross observation on the thickness of the whole ACL.

For tensile testing, the femoral-ACL-tibial complex specimen was mounted on to a tensile tester (PTM-250W, Orientec) using a set of specially-designed grips. The tibia was flexed at $45^{\circ}$ against the femur. The knee was rotated approximately $90^{\circ}$ internally to remove the normal distortion of the ACL, ${ }^{24}$ although the loads were not fully applied to all portions of the bundle during tensile testing. The specimens were tested with the axis of loading along the anatomical axis of the ACL (ligament axis) at $45^{\circ}$ of knee flexion. Prior to the tensile test, the specimen was preconditioned with a static preload of $0.5 \mathrm{~N}$ for five minutes, followed by ten cycles of loading and unloading ( $3 \%$ strain) with a crosshead speed of $5 \mathrm{~mm} / \mathrm{min}$. Then, each specimen was stretched to failure using the same conditions with preconditioning at a crosshead speed of $20 \mathrm{~mm} / \mathrm{min}$ while being kept moist with a physiological saline solution. This speed was chosen because it was frequently used in previous studies with the rabbit ACL. ${ }^{25-27}$ The load-elongation curve was obtained in the tensile test. The structural properties of maximum load, stiffness and elongation at failure were determined directly from the load-elongation curves. The maximum load was defined as the load at the point of failure of the specimen. The stiffness was defined by the slope of the load-elongation curve, which was determined by applying a least-squares linear regression analysis to the data curve between the endpoint of the toe region and the point that starts to bend before failure.

Mechanical testing of fascicles harvested from the ACL. We measured the mechanical properties of fascicles harvested from the ACL, according to previous studies reported by Yamamoto et al. ${ }^{18}$ Collagen fascicles with a diameter of approximately $300 \mu \mathrm{m}$ and a length of $10 \mathrm{~mm}$ were carefully dissected with a scalpel parallel to the axis of the ACL. In preparation of collagen fascicles, bone plugs were carefully harvested with a chisel and scalpel. Their size was approximately $5 \mathrm{~mm} \times 5 \mathrm{~mm}$. The cross-sectional area of the collagen fascicle was calculated indirectly from the lateral image of the collagen fascicle immersed in physiological saline solution at $37^{\circ} \mathrm{C}$ enlarged by a low-magnification microscope (SMZ-2Z, Nikon, Tokyo, Japan). An image was taken with a change-coupled device camera (Panasonic), and processed with a video dimension analyser (Percept Scope C3160, Hamamatsu Photonics). The diameter was measured from 36 directions, while the fascicle was intermittently rotated with a stepping motor at an angular interval of $5^{\circ}$. The cross-sectional area was calculated by averaging these diameters, assuming that the 
Table I. The anteroposterior translation of the knee and the tissue dimensions of the anterior cruciate ligament $(A C L)$ (mean (SD)) ( $n=7$ for each group)

\begin{tabular}{lllllll}
\hline \multirow{2}{*}{ Group } & \multicolumn{9}{l}{ Anteroposterior translation $(\mathbf{m m})$} & & \\
\cline { 2 - 6 } & $\mathbf{3 0 ^ { \circ }}$ & $\mathbf{6 0}^{\circ}$ & $\mathbf{9 0}^{\circ}$ & ACL length $(\mathbf{m m})$ & Cross-sectional area $\left(\mathbf{m m}^{2}\right)$ \\
\hline I & $2.9(0.3)^{*}$ & $2.7(0.4)^{*}$ & $2.1(0.4)^{*}$ & $11.1(0.1)^{*}$ & $5.0(1.5)$ \\
II & $3.2(0.3)^{*}$ & $2.7(0.4)^{*}$ & $1.7(0.5)^{\dagger}$ & $11.3(0.6)^{*}$ & $5.7(2.1)$ \\
III & $2.7(0.6)^{*}$ & $2.2(0.8)^{\ddagger}$ & $1.7(0.7)^{*}$ & $10.9(0.2)^{*}$ & $5.4(1.8)$ \\
IV & $1.6(0.3)$ & $1.2(0.4)$ & $0.6(0.2)$ & $9.9(0.2)$ & $5.0(0.6)$ \\
\hline
\end{tabular}

* significantly different from group IV $(p<0.001)$

$\dagger$ significantly different from group IV $(p=0.006)$

₹ significantly different from group IV $(p=0.004)$

cross-section was circular. These measurements were taken at a $2 \mathrm{~mm}$ position proximal to the middle, and at a $2 \mathrm{~mm}$ position distal to the middle. A mean cross-sectional area was obtained from these two sets of measurements. After the cross-sectional area measurement, we evaluated the mechanical properties of the collagen fascicles from the ACL using a microtensile tester. Acrylic blocks were attached to both ends of the bone-fascicle-bone complex with cyanoacrylate adhesive. One of the blocks was attached to a load cell (LVS-1KA, Kyowa, Tokyo, Japan) and the other was attached to the crosshead of the linear stage (LU09200AKL1-P5Z0, Nihonseiko, Tokyo, Japan). Tensile tests were carried out by moving the stage with a microprocessor-controlled stepping motor at a speed of $10 \mathrm{~mm} / \mathrm{min}$ (UPD566TG30-A, Orientatal Motor, Tokyo, Japan). For the measurement of strain, two markers were drawn on a collagen fascicle with a nigrosine stain about $5 \mathrm{~mm}$ apart; the strain measured with this method is the strain on the specimen surface. ${ }^{17}$ The distance between the markers was measured with the previously described video dimension analyser using its tracking function. According to our pilot study, the total error including electrical noise was SD $0.36 \%$. For the gauge length of specimens in the present study $(5 \mathrm{~mm})$ the total error was estimated to be $0.18 \mathrm{~mm}$. During tensile testing, specimens were immersed in physiological saline solution at $37^{\circ} \mathrm{C}$. Tensile load and the distance between the two markers were recorded on a personal computer (PC386-GE, Epson, Nagano, Japan). From the stress-strain data, we obtained the tensile strength, the tangent modulus and the strain at failure of the fascicles. The tangent modulus was defined as the slope of the stress-strain curve between $5 \%$ and $10 \%$ strain using a least-squares method.

Histological observations. In each limb intended for histological observation, the femoral-ACL-tibial complex was resected and fixed in a buffered $10 \%$ formalin solution, decalcified, and cast in paraffin blocks. For each block, we set a microtome so that the midsubstance was sectioned parallel to the longitudinal axis. The central portion of the whole specimen in the sagittal plane was marked on the surface of the block. Half of the specimen was resected until the central sagittal plane could be observed. Then, five $5 \mu \mathrm{m}$ continuous sections were obtained and were stained with haematoxylin and eosin for histological examination. Two of the co-authors (EK, HT) performed the histological studies, independently in a blinded manner using light microscopy. The cellularity, shape of the nuclei and collagen striations in the ligament substance were recorded.

Statistical analyses. All data were shown as means with SD. For each parameter, one-way analysis of variance (ANOVA) was performed among the groups. When a significant effect was obtained, a post hoc test with Fisher's protected least-significant difference test was made for multiple comparisons. A commercially-available software program (Stat View; SAS Institute, Cary, North Carolina) was used for statistical calculation. The significance level was set at $\mathrm{p}=0.05$.

\section{Results}

Anteroposterior translation of the knee. Concerning the anteroposterior translation of the knee, the ANOVA showed significant differences between the groups at each angle of flexion $(\mathrm{p}<0.001)$. The post hoc test indicated that groups I, II and III were significantly greater than group IV (control) at $30^{\circ}, 60^{\circ}$ and $90^{\circ}$ of flexion (Table I), whereas there were no significant differences between groups I, II and III.

Gross observation of inside the knee joint. In groups I and II at 12 weeks, the ACL was enveloped by a thin synovium-like tissue whereas in group III the ACL was enveloped by a thick synovium-like tissue at 12 weeks. In these three injured groups, the transected portions could not be distinguished from the other portions, and the infrapatellar fat pad was commonly fibrotic. No abnormal intraarticular findings, including cartilage degeneration and osteochondral regeneration, were observed in any group. Tissue dimension of the ACL. ANOVA showed a significant difference $(\mathrm{p}<0.001)$ in the length of the ACL between the groups (Table I). The post hoc test indicated that the length of the ACL in groups I, II and III was significantly greater than that in group IV $(p<0.001)$, whereas there were no significant differences among the three injured groups. Specifically, the ACL length in groups I, II 


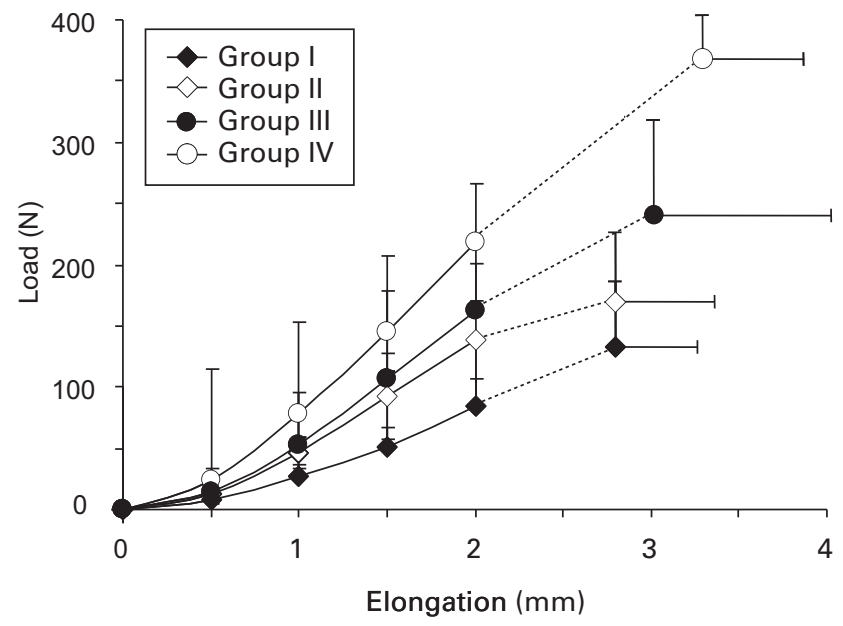

Fig. 2

Graph showing mean load-elongation curves of the femoral-anterior cruciate ligament-tibial complexes. Each error bar represents the SD.

Table II. Mean absolute values of the structural properties of the femoral-anterior cruciate ligament-tibial complex (mean (SD)) ( $\mathrm{n}=7$ for each group)

\begin{tabular}{|c|c|c|c|}
\hline Group & Maximum load (N) & Stiffness $(\mathrm{N} / \mathrm{mm})$ & $\begin{array}{l}\text { Elongation at } \\
\text { failure }(\mathrm{mm})\end{array}$ \\
\hline I & $134.3(49.6)^{*}$ & $73.9(20.9)^{*}$ & $2.8(0.4)$ \\
\hline II & $169.5(53.4)^{*}$ & $78.0(30.7)^{*}$ & $2.8(0.5)$ \\
\hline III & $239.4(83.5)^{*+\ddagger}$ & $115.8(40.1)^{5 \uparrow \uparrow^{* *}}$ & $3.0(1.1)$ \\
\hline IV & $369.6(28.8)$ & $153.0(21.6)$ & $3.3(0.6)$ \\
\hline \multicolumn{4}{|c|}{ * significantly different from group IV $(p<0.001)$} \\
\hline \multicolumn{4}{|c|}{ \# significantly different from group I $(p=0.002)$} \\
\hline \multicolumn{4}{|c|}{$\S$ significantly different from group IV ( $p=0.026)$} \\
\hline \multicolumn{4}{|c|}{ II significantly different from group II ( $p=0.0245)$} \\
\hline \multicolumn{4}{|c|}{ * * significantly different from group I $(p=0.014)$} \\
\hline
\end{tabular}

and III was elongated by approximately $1 \mathrm{~mm}$, representing approximately $10 \%$ of the original length of the whole ACL. Regarding the whole cross-sectional area, the ANOVA indicated no significant differences between the groups (Table I).

Structural properties of the femoral ACL-tibial complex. Regarding failure modes, all specimens failed at the midsubstance in groups I and II, whereas the ACL insertion was avulsed in four and seven specimens in groups III and IV, respectively. The load-elongation curves showed marked differences between the control group and the three injured groups (Fig. 2). Table II shows the structural properties of the femoral-ACL-tibial complexes. The ANOVA demonstrated a significant difference in the maximum load $(\mathrm{p}<0.001)$ and stiffness $(\mathrm{p}<0.001)$ between the groups.

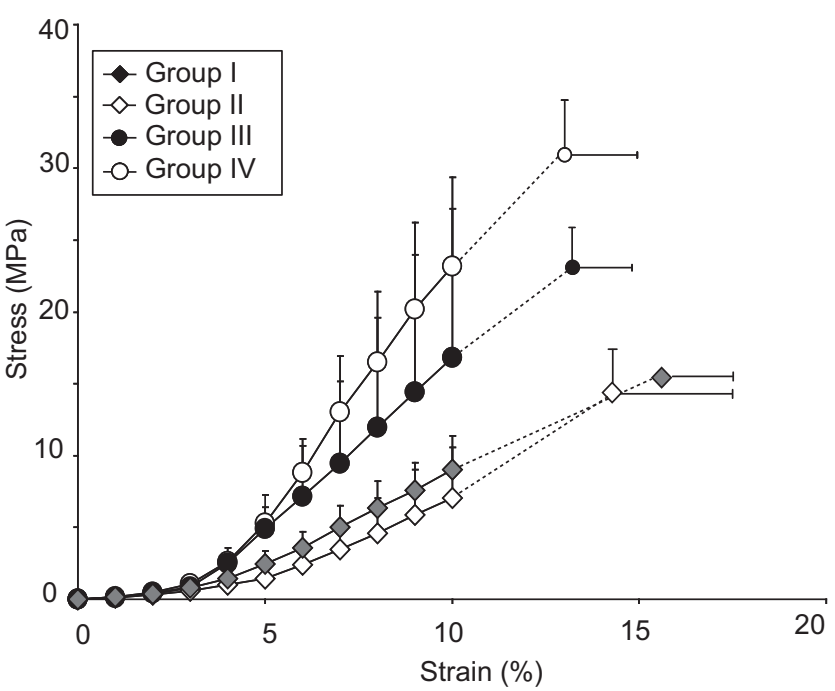

Fig. 3

Graph showing mean stress-strain curves of fascicles of the anterior cruciate ligament. Each error bar represents the SD.

The post hoc test showed that the maximum load and the stiffness in group III were significantly greater than those in groups I $(\mathrm{p}=0.002, \mathrm{p}=0.014)$, and II $(\mathrm{p}=0.032$, $\mathrm{p}=0.0245), \quad$ respectively, but significantly lower $(\mathrm{p}=0.001, \mathrm{p}=0.026)$ than in group IV. There were no significant differences in maximum load or stiffness between groups I and II $(0.2603, \mathrm{p}=0.7964)$. Regarding the elongation at failure of the femoral-ACL-tibial complex, the ANOVA revealed no significant differences between the four groups $(\mathrm{p}>0.1826)$ (Table II).

Mechanical properties of fascicles from the ACl. All fascicle specimens were torn between the two gauge-length markers drawn on fascicle specimens. The mean stress-strain relation curves are shown in Figure 3. The mechanical properties of the fascicles from the ACL are shown in Table III. ANOVA demonstrated a significant difference in the tensile strength $(\mathrm{p}<0.001)$ and the tangent modulus $(\mathrm{p}=0.001)$ between the groups. The post hoc test showed that the tensile strength and the tangent modulus of group III was significantly greater than those of groups I and II ( $p=0.002$, $\mathrm{p}=0.0174, \mathrm{p}=0.005, \mathrm{p}=0.022$, respectively), but significantly lower $(\mathrm{p}=0.0064, \mathrm{p}=0.04)$ than those of group IV. There were no significant differences in the tensile strength and the tangent modulus between groups I and II $(p=0.6392, p=0.9007)$. Regarding the strain at failure, the ANOVA revealed no significant differences among the four groups (Table III).

Histological observations. In the control group, a thin synovial membrane enveloped the substance of the ligament, which consisted of closely packed collagen fibres that aligned longitudinally with a periodic crimp pattern. Fibroblasts were sparsely scattered between the collagen 
Table III. Absolute values of the mechanical properties of fascicles from the anterior cruciate ligament (mean (SD)) ( $n=5$ for each group)

\begin{tabular}{llll}
\hline Group & Tensile strength (MPa) & Tangent modulus (MPa) & Strain at failure (\%) \\
\hline I & $14.3(2.7)^{*}$ & $117.0(59.1)^{*}$ & $14.6(3.5)$ \\
II & $15.4(2.2)^{*}$ & $121.7(33.5)^{*}$ & $15.5(1.9)$ \\
III & $23.3(3.8)^{\dagger \neq \S}$ & $216.0(62.4)^{\text {I**+† }^{*}}$ & $13.4(1.9)$ \\
IV & $31.0(5.7)$ & $299.3(72.9)$ & $12.8(1.9)$ \\
\hline * &
\end{tabular}

* significantly different from group IV $(p<0.001)$

† significantly different from group IV $(p=0.006)$

‡ significantly different from group II $(p=0.005)$

$\S$ significantly different from group I $(p=0.002)$

II significantly different from group II $(p=0.04)$

** significantly different from group II $(p=0.022)$

†† significantly different from group I $(p=0.0174)$

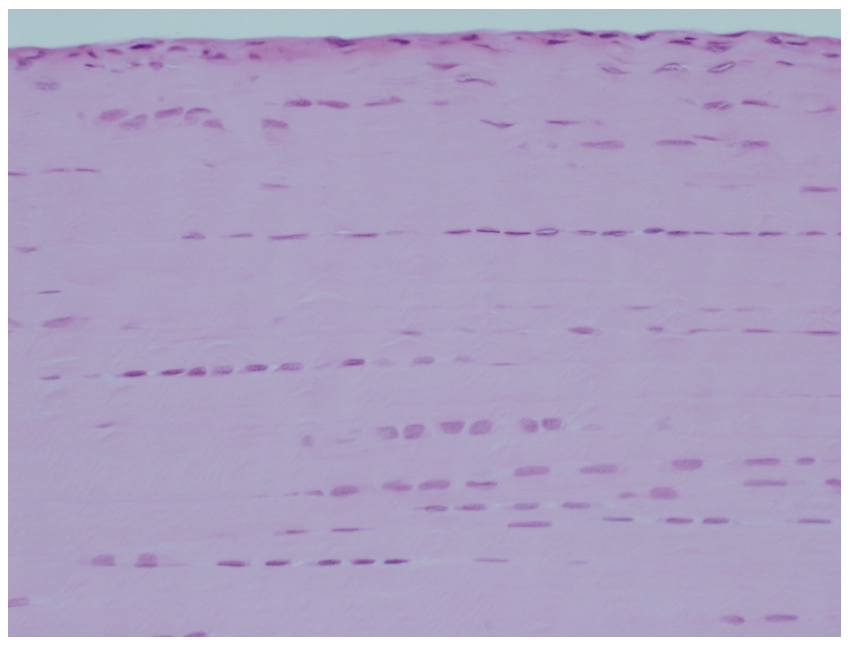

Fig. $4 a$

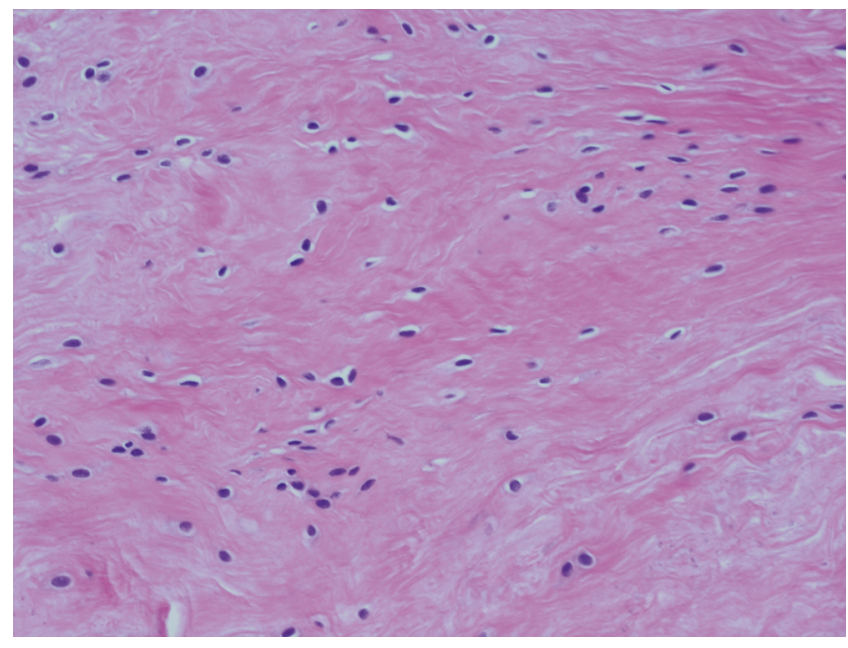

Fig. 4b

Photomicrographs showing the histological findings in the midsubstance of the anterior cruciate ligament with light microscopy (original magnification $\times 100)$, a) histology of group IV, b) histology of group III. In the midsubstance we occasionally observed granulation tissue, in which collagen bundles appeared to be irregular, separated and fragmented, with numerous cells having a small round nucleus in the treated groups.

fibres (Fig. 4a). In the elongated portion of the midsubstance we occasionally observed granulation-like tissue, in which collagen bundles appeared to be irregular, separated and fragmented, with numerous cells having a small round nucleus (Fig. 4b). We found no bone formation in the midsubstance of the injured ACL. However, we could not find any obvious differences among the injured groups. A small area of articular cartilage in each knee showed mild degeneration, such as fibrillation.

\section{Discussion}

This study clearly demonstrated that the immediate application of $12.5 \mu \mathrm{g}$ OP-1 after the creation of a controlled injury to the ACL significantly increased the stiffness of the midsubstance of the injured ACL at 12 weeks. In addition, the results of the mode of failure and the maximum load of the
femoral-ACL-tibial complex suggested that this application significantly increased the maximum load of the injured ACL midsubstance at 12 weeks. The application of $12.5 \mu \mathrm{g}$ OP-1 significantly increased the tensile strength and the tangent modulus of fascicles harvested from the injured ACL at this time. These results implied that the local application of OP1 significantly increases the structural properties of the injured ACL via an increase in the mechanical properties of collagen fascicles regenerated in the injured portion. However, this study suggested that OP-1 did not significantly affect the anteroposterior translation of the knee or the length of the ACL. These results also suggested that OP-1 does not restore the elongated ACL back to its normal length.

There are some limitations of this study. The first is that we did not quantify the concentration of OP-1 over time after application. Vukicevic et $\mathrm{al}^{28}$ demonstrated that sys- 
temic clearance of the active form of OP-1 is rapid. However, it has been known that the in vivo application of some growth factors, including OP-1, chronically enhances tissue healing and remodelling. ${ }^{29-32}$ The second limitation is that the ACL injury created in this study is not the same as partial ACL injuries in humans, and the timing of the application of the OP-1 would not be immediate in the clinical setting. However, we believe that this model is the most acceptable partial injury model in comparison with previous models, which were created by sharp hemi-resection of the midsubstance. ${ }^{33-36}$ The third limitation is that the evaluation was performed only at 12 weeks after surgery. The time-dependent change in the effects of interleukin (IL)-1 receptor antagonist application on the stress-shielded patellar tendon remains to be clarified in further studies over longer periods, although the most significant effect of stress shielding on the patellar tendon is found at three weeks, as in our earlier studies using the same animal model, and we could not clarify when the effect of growth factor occurred during the experimental period..$^{5,22}$ The fourth limitation is that we did not perform molecular-biological examinations. Beyond these limitations, however, we believe that this study provides valuable information on the effect of OP-1 on this model of elongation-type ACL injury.

Many of the previous studies used collagen, blood clot and fibrin sealant as delivery vehicles. ${ }^{37-39}$ Recently, however, Jelic et $\mathrm{al}^{40}$ and Cheline, Reddi and Martin ${ }^{41}$ reported significant effects of OP-1 applied with PBS as a vehicle on bone formation. In the present study, PBS was used as a delivery vehicle to apply OP-1 to the injured ACL. Even after surgery, the knee joint was filled with the PBS containing OP-1, although we could not quantify the filling period. Therefore, PBS was a reasonable vehicle to apply OP-1 to the injured ACL. In addition, our previous study ${ }^{42}$ showed that vascular endothelial growth factor applied with PBS in the same manner as used in the present study significantly promoted healing of the ACL, also indicating that PBS can be used as a vehicle to apply OP-1 to the injured ACL.

Natural ligament and tendon tissues have a hierarchical structure composed of bundles, fascicles, fibrils and fibres. ${ }^{43}$ The mechanical properties of these tissues depend on the mechanical properties of fascicles, mechanical interaction among fascicles, and mechanical interaction among other minor matrix proteins and fascicles. It is important to clarify which change among these three components causes the gross change in the mechanical properties of the ligament and tendon tissues. For example, Yamamoto, Hayashi and Yamamoto ${ }^{44}$ reported that complete stress deprivation does not significantly change the mechanical properties of fascicles, but affected the mechanical interaction among fascicles or mechanical interaction among other minor matrix proteins and fascicles, resulting in deterioration of the mechanical properties of the patellar ligament. Recent studies ${ }^{22,45}$ have shown that an in vivo local application of antagonists of TGF- $\beta 1$ and IL- 1 does not significantly affect the mechanical properties of fascicles, but effects the mechanical interaction among fascicles and the interaction among other minor matrix proteins and fascicles, increasing the mechanical properties of the stressshielded patellar ligament. In the present study, therefore, we performed the microtensile tests on collagen fascicles harvested from the ACL. Interestingly, we found that OP-1 significantly increased the mechanical properties of the fascicles. This implied that the applied OP-1 enhances fibroblasts to generate stronger and stiffer fascicles in healing the injured ACL.

We can speculate on a few possible mechanisms concerning the in vivo effect of OP-1 on the biomechanical properties of the injured ACL. Tsai et $\mathrm{al}^{12}$ reported that OP-1 stimulated cell proliferation, type I collagen gene expression, and aggrecan mRNA expression in cultured ligament cells. Bobacz et $\mathrm{al}^{46}$ reported that OP-1 and their specific type I and II receptors were expressed in fibroblasts of the bovine intra-articular ligament, and that OP-1 induced aggrecan mRNA expression in cultured fibroblasts derived from bovine ligament. Therefore, the first possible mechanism is that the application of OP- 1 may improve the collagen network or the cross-link profile in the injured ACL. On the other hand, Yeh and Lee ${ }^{47}$ showed that OP-1 regulated gene expression of insulin-like growth factor (IGF)-1 and 2. It is known that IGF-1 and 2 are expressed in the early phase of tendon and ligament healing, and enhance the healing process. ${ }^{48}$ Vukicevic et $\mathrm{al}^{28}$ reported that OP-1 inhibited inflammatory cytokine (IL-1 and tumour necrosis factor- $\alpha$ )-mediated intercellular adhesive molecule-1 production. Recently, it has been shown that the inhibition of IL-1 $\beta$ significantly reduced the mechanical deterioration of the patellar ligament due to stress deprivation. ${ }^{22}$ Therefore, the second possible mechanism is that the application of OP-1 may induce IGF and/or inhibit inflammatory cytokines in the injured ACL. ${ }^{49}$ Further studies should be conducted to verify which mechanism explains the results in the present study.

In the histological evaluation we found no bone formation within the ACL treated with OP-1, although two studies $^{50,51}$ reported that OP-1 induced the formation of an ossicle in a transection model of rat tendo Achillis. The difference between the present study and the previous studies implied that the in vivo effect of OP-1 on ligament injuries may be different between the intra- and extraarticular environments or the ACL and the tendo Achillis. In our study we did not detect any differences in the histological findings among the injured groups. In general, the injured lesion and the uninjured midsubstance were clearly distinguished in the transection model. In the elongated injury model used in the present study, however, the minimally-ruptured portions of collagen fibres or fascicles were scattered among the apparently intact midsubstance, so that it is difficult to detect the collagen microruptures themselves using a microscope. ${ }^{4,5}$ Therefore, the specific healing reaction by fibroblasts with or without the growth 
factor treatment was also difficult to observe precisely microscopically. This may explain why histologically we did not detect any differences in the present study. This may be one of the characteristics in the overstretched model, because we did detect some histological differences using an in situ frozen-thawed ACL model in our previous studies. ${ }^{26,27}$ In future studies, the effect of the application of OP-1 may be detected by molecular-biological examinations.

It is hard to infer clinical relevance directly from this study, because despite the improvement in the mechanical properties of the injured ACL it remained lengthened. However, it is known that an application of OP-1 has been clinically tried to treat nonunion in fractures and to promote spinal fusion. ${ }^{9,10}$ Therefore further study of the administration of OP-1 as a therapeutic strategy to treat the overstretched ACL injury is appropriate.

This study was supported financially in part by the Grants-in-Aid for Scientific Research (17591543 and 16390425) from the Ministry of Education, Culture, Sports, Science and Technology, Japan.

No benefits in any form have been received or will be received from a commercial party related directly or indirectly to the subject of this article.

\section{References}

1. Hirshman HP, Daniel DM, Miyasaka K. The fate of unoperated knee ligament injuries. In: Daniel D, Akeson W, O'Connor J, eds. Knee ligaments: structure, function injury and repair. New York: Raven, 1990:481-503.

2. Hughston JC. Complications of anterior cruciate ligament surgery. Orthop Clin North Am 1985;16:237-40.

3. Sachs RA, Daniel DM, Stone ML, Garfein RF. Patellofemoral problems after anterior cruciate ligament reconstruction. Am J Sports Med 1989;17:760-5.

4. Kondo E, Yasuda K, Yamanaka M, Minami A, Tohyama H. Biomechanical evaluation of a newly devised model for the elongation-type anterior cruciate ligament injury with partial laceration and permanent elongation. Clin Biomech 2003;18:942 9.

5. Kondo E, Yasuda K, Yamanaka M, Minami A, Tohyama H. Effects of adminis tration of exogenous growth factors on biomechanical properties of the elongationtype anterior cruciate ligament injury with partial laceration. Am J Sports Med 2005;33:188-95

6. van Beuningen HM, van der Kraan PM, Arntz OJ, van den Berg WB. Trans forming growth factor-beta 1 stimulates chondrocyte proteoglycan synthesis and induces osteophyte formation in the murine knee joint. Lab Invest 1994;71:279-90.

7. Hulth A, Johnell $\mathbf{0}$, Miyazono $\mathbf{K}$, et al. Effect of transforming growth factor-beta and platelet-derived growth factor-BB on articular cartilage in rats. J Orthop Res 1996;14:547-53

8. Bakker AC, van de Loo FA, van Beuningen HM, et al. Overexpression of active TGF-beta-1 in the urine knee joint: evidence for synovial-layer-dependent chondroosteophyte formation. Osteoarthritis Cartilage 2002;9:128-36.

9. Friedlaender GE, Perry CR, Cole JD, et al. Osteogenic protein-1 (bone morphogenetic protein-7) in the treatment of tibial nonunions. J Bone Joint Surg [Am] 2001;83-A:151-8

10. Kanayama $\mathbf{M}$, Hashimoto $\mathbf{T}$, Shigenobu $\mathbf{K}$, et al. A prospective randomized study of posterolateral lumbar fusion using osteogenic protein-1 (OP-1) versus local autograft with ceramic bone substitute: emphasis of surgical exploration and histologic assessment. Spine 2006;31:1067-74.

11. Sakou T. Bone morphogenetic proteins: from basic studies to clinical approaches Bone 1998;22:591-603

12. Tsai AD, Yeh LC, Lee JC. Effects of osteogenic protein-1 (OP-1, BMP-7) on gene expression in cultured medial collateral ligament cells. J Cell Biochem 2003;90:777-91.

13. Cook SD. Preclinical and clinical evaluation of osteogenic protein-1 (BMP-7) in bony sites. Orthopedics 1999;22:669-71.

14. Koepp HE, Sampath KT, Kuettner KE, Homandberg GA. Osteogenic protein-1 (OP-1) blocks cartilage damage caused by fibronectin fragments and promotes repair by enhancing proteoglycan synthesis. Inflamm Res 1999;48:199-204.

15. Sampath TK, Miliakal JC, Hauschka PV, et al. Recombinant human osteogenic protein-1 (hOP-1) induces new bone formation in vivo with a specific activity comparable with natural bovine osteogenic protein and stimulates osteoblast proliferation and differentiation in vitro. J Biol Chem 1992;267:20352-62.
16. No authors listed. Rules and regulations of the annual care and use committee. Hokkaido University. http://www.igm-hokudai.ac.jp/lae/index-j.html (date last accessed 11 August 2008)

17. Mihelic R, Pecina M, Jelic M, et al. Bone morphogenetic protein-7 (osteogenic protein-1) promotes tendon graft integration in anterior cruciate ligament reconstruction in sheep. Am J Sports Med 2004;32:1619-25.

18. Yamamoto E, Hayashi K, Yamamoto N. Mechanical properties of collagen fascicles from stress-shielded patellar tendons in the rabbit. Clin Biomech 1999;14:41825

19. Yamamoto E, Hayashi K, Yamamoto N. Mechanical properties of collagen fascicles from the rabbit patellar tendon. J Biomech Eng 1999;121:124-31.

20. Ikema Y, Tohyama H, Yamamoto E, Kanaya F, Yasuda K. Ex vivo infiltration of fibroblasts into the tendon deteriorates the mechanical properties of tendon fascicles but not those of tendon bundles. Clin Biomech 2007;22:120-6.

21. Azuma C, Tohymama H, Nakamura H, Kanaya F, Yasuda K. Antibody neutralization of TGF-beta enhances the deterioration of collagen fascicles in a tissue-cultured tendon matrix with ex vivo fibroblast infiltration. J Biomech 2007;40:2184-90.

22. Miyatake $\mathbf{S}$, Tohyama $\mathbf{H}$, Kondo $\mathbf{E}$, et al. Local administration of interleukin-1 receptor antagonist inhibits deterioration of mechanical properties of the stressshielded patellar tendon. J Biomech 2008;41:884-9.

23. Jackson DW, Grood ES, Goldstein JD, et al. A comparison of patellar tendon autograft and allograft used for anterior cruciate ligament reconstruction in the goat model. Am J Sports Med 1993:21:176-85.

24. Wo SL, Newton PO, MacKenna DA, Lyon RM. A comparative evaluation of the mechanical properties of the rabbit medial collateral and anterior cruciate ligaments. J Biomech 1992;25:377-86.

25. Woo SL, Gomex MA, Seguchi Y, Endo CM, Akeson WH. Measurement of mechanical properties of ligament substance from a bone-ligament-bone preparation. J Orthop Res 1983:1:22-9.

26. Sakai T, Yasuda K, Tohyama H, et al. Effects of combined administration of transforming growth factor-beta1 and epidermal growth factor on properties of the in situ frozen anterior cruciate ligament in rabbits. J Orthop Res 2002;20:1345-51.

27. Azuma H, Yasuda K, Tohyama H, et al. Timing of administration of transforming growth factor-beta and epidermal growth factor influences the effect on material properties of the in situ frozen-thawed anterior cruciate ligament. $J$ Biomech 2003;36:373-81

28. Vukicevic S, Basic V, Rogic D, et al. Osteogenic protein-1 (bone morphogenetic protein-7) reduces severity of injury after ischemic acute renal failure in rat. $J$ Clin Invest 1998;102:202-14.

29. Letson AK, Dahners LE. The effect of combinations of growth factors on ligament healing. Clin Orthop 1994;308:207-12

30. Lee J, Green MH. Amiel D. Synergistic effect of growth factors on cell outgrowth from explants of rabbit anterior cruciate and medial collateral ligaments. J Orthop Res 1995:13:435-41.

31. DesRosiers EA, Yahia L, Rivard CH. Proliferative and matrix synthesis response of canine anterior cruciate ligament fibroblasts submitted to combined growth factors. J Orthop Res 1996;14:200-8.

32. Molloy T, Wang Y, Murrell G. The roles of growth factors in tendon and ligament healing. Sports Med 2003;33:381-94.

33. O'Donoghue DH, Rockwood CA Jr, Frank GR, Jack SC, Kenyon R. Repair of the anterior cruciate ligament in dogs. J Bone Joint Surg [Am] 1966;48-A:503-19.

34. Hefti FL, Kress A, Fasel J, Morscher EW. Healing of the transected anterior cruciate ligament in the rabbit. J Bone Joint Surg [Am] 1991;73-A:373-83.

35. Wiig ME, Amiel D, VandeBerg J, et al. The early effect of high molecular weight hyaluronan (hyaluronic acid) on anterior cruciate ligament healing: an experimental study in rabbits. J Orthop Res 1990;8:425-34.

36. Ng GY, Oakes BW, McLean ID, Deacon OW, Lampard D. The long-term biomechanical and viscoelastic performance of repairing anterior cruciate ligament after hemitransection injury in a goat model. Am J Sports Med 1996;24:109-17.

37. Hildebrand KA, Woo SL, Smith DW, et al. The effects of platelet-derived growth factor-BB on healing of the rabbit medial collateral ligament: an in vivo study. $\mathrm{Am}$ J Sports Med 1998;26:549-54.

38. Louwerse RT, Heyligers IC, Klein-Nulend J, et al. Use of recombinant human osteogenic protein-1 for the repair of subchondral defects in articular cartilage in goats. J Biomed Mater Res 2000;49:506-16.

39. Cook SD, Salkeld SL, Patron LP. Bone defect healing with an osteogenic protein1 device combined with carboxymethylcellulose. J Biomed Mater Res B Appl Biomater 2005;75:137-45.

40. Jelic M, Pecina M, Haspl M, et al. Regeneration of articular cartilage chondral defects by osteogenic protein-1 (bone morphogenetic protein-7) in sheep. Growth Factors 2001:19:101-13

41. Cheline AJ, Reddi AH, Martin RB. Bone morphogenetic protein-7 selectively enhances mechanically induced bone formation. Bone 2002;31:570-4 
42. Ju YJ, Tohyama H, Kondo $\mathbf{E}$, et al. Effects of local administration of vascular endothelial growth factor on properties of the in situ frozen-thawed anterior cruciate ligament in rabbits. Am J Sports Med 2006;34:84-91.

43. Kastelic J, Galeski A, Baer E. The multicomposite structure of tendon. Connective Tissue Res 1978;6:11-23.

44. Yamamoto E, Hayashi K, Yamamoto N. Effects of stress shielding on the transverse mechanical properties of rabbit patellar tendons. Biomech Eng 2000;122:608-14

45. Katsura T, Tohyama H, Kondo E, Kitamura N, Yasuda K. Effects of administration of transforming growth factor (TGF)-betal and anti-TGF-beta1 antibody on the mechanical properties of the stress-shielded patellar tendon. J Biomech 2006:39:2566-72

46. Bobacz K, Ullrich R, Amoyo L, et al. Stimulatory effects of distinct members of the bone morphogenetic protein family on ligament fibroblasts. Ann Rheum Dis 2006;65:169-77.

47. Yeh LC, Lee JC. Co-transfection with the osteogenic protein (OP)-1 gene and the insulin-like growth factor (IGF)-1 gene enhanced osteoblastic cell differentiation. Biochim Biophys Acta 2006;1763:57-63.
48. Abrahamsson So. Similar effects of recombinant human insulin-like growth factor-I and II on cellular activities in flexor tendons of young rabbits: experimental studies in vitro. J Orthop Res 1997;15:256-62.

49. Huch K, Wilbrink B, Flechtenmacher $\mathbf{J}$, et al. Effects of recombinant human osteogenic protein 1 on the production of proteoglycan, prostaglandin E2, and interleukin-1 receptor antagonist by human articular chondrocytes cultured in the presence of interleukin-1beta. Arthritis Rheum 1997;40:2157-61.

50. Forslund C, Aspenberg P. OP-1 has more effect than mechanical signals in the control of tissue differentiation in healing rat tendons. Acta Orthop Scand 1998;69:622-6

51. Aspenberg P, Forslund C. Bone morphogenetic proteins and tendon repair. Scand J Med Sci Sports 2000;10:372-5. 